\title{
SERVING VARIEGATED AUDIENCES: FROM RANKING ORIENTED EVALUATION TO MISSION ORIENTED EVALUATION
}

\author{
A.A.M. PRINS AND J.B. SPAAPEN
}

A cademic researchers are under an ever growing pressure to demonstrate that the work they do not only has excellent scientific value but is also relevant to society's questions and challenges. Many governments have introduced targeted funding programs that demand societal impact of academic research, and so has the European Commission, in particular with the Grand Societal Challenges of the Horizon 2020 framework program. As a rule, such funding schemes expect academic researchers to team up with partners in society, depending on the topic of research coming from industry, the public sector or society at large. And this tendency to involve society in the setting of academic research agenda's may go even further witness the National Science Agenda introduced in 2014 by the Dutch government. In this program, all Dutch citizens were asked to submit questions they deemed worth to research. ${ }^{1}$

The consequence of this policy to steer academic research more into the direction of society and it's problems is that academic researchers have come to operate in a much wider context than the university context they were used to, and that they have to review the knowledge that they produce and the ways they communicate this with their newly emerging environment. This is not to say that before the changes in governmental funding policy academics did not interact with society, but both the scale and the mandatory character of the policy is very different than in the past. The societal challenges part of H2O2O contains about 30 billion euros for the six year period between 2014 and 2020 (of the total budget of around 80 billion euro). Clearly, these changes also have consequences for the way research is evaluated; after all, the value of research needs to be assessed against a much wider context than the performance in the international literature. Next to excellence, societal impact then becomes an important criterion in research evaluation.

As Bornmann in his 2013 literature review shows, there is not a lot of consensus yet about what societal impact is or how to evaluate it. But much of the literature about research impact assessment stresses the importance of the network of societal stakeholders related to academic research (Bornmann 2013). Recent experiences in evaluation practices such as the British REF UK 2014 show considerable diversity of such networks, and of the ways to achieve impact (Manville et al., 2015). In this paper we will review the diversity of such networks for a number of research organizations inside academia, and the possible consequences for evaluation practices. We will argue that this diversity reflects the organizational and social characteristics of the specific network in which research organizations work, and as such requires a greater focus on these specific characteristics and on the mission of the units to be evaluated. This shift in evaluation focus implies a diminishing role for comparison with other units (unless they have the same mission), something that is an important goal of evaluation for many governors, managers and administrators who often are ranking oriented. But we think that the kind of evaluation we have in mind is more adequate for the societal networks in which research takes place these days. And we also think that evaluation still can be conducted in a systematic and robust manner. A shift from comparison oriented evaluations to the specific characteristics and mission of research units offers the opportunity to learn from and improve stakeholder relations, and thus, arguably, the impact of research. Mission oriented evaluations arguably help both the management of an institute and the (interaction with) the environment.

\section{THE SOCIETAL NETWORK OF INNOVATIVE RESEARCH}

Research that helps innovate society, whether this is through new technologies or new forms of organisation, new insights or processes, or otherwise, is mostly part of multi-actor endeavors, with participants coming from both science and society. This is certainly the case for the many research institutes that operate outside academia, institutes that have a specific mission for example in health research, environmental or energy studies. Typically, the research agendas of such institutes are developed in collaboration with relevant stakeholders, and the results of the research work is often published in media that have a wider reach than the academic community (Spaapen and Van Drooge 2011: 214).

But more and more, institutes operating within the academic sphere (universities, academy institutes, and other) also perform their research

The request of the Dutch government to come up with questions for the National Research Agenda resulted in close to 12,000 questions by the general Dutch public and a vast number of public and private organisations. After an intricate procedure led by the Dutch Academy of Arts and Sciences the agenda now presents 140 overarching scientific questions. The plan is that Dutch scientific research focuses on these in the coming years. (http://www.wetenschapsagenda.nl/?lang=en) 
in the context of issues and challenges in policy or society at large. The networks that are formed by these wider communities are as a rule more diverse and often also more temporary than traditional academic networks. Both researchers and policy makers have to review their perspective on this position, both in terms of how they interact with the broader environment (for example with regard to their research agenda) and in terms of how they assess the success of new forms of collaboration. The networks are characterized by a variety of scientific stakeholders (various disciplines) and stakeholders from society, be it industry, government or society at large. Somehow, all these different backgrounds, interests and work practices have to be attuned in new arrangements in which goals, performance and monitoring and evaluation have to be elaborated. Elsewhere, we have collaborated with many colleagues to analyse such networks and researched what the consequences could be for the evaluation (www.siampi.eu). ${ }^{2}$ The analysis there focused on the different types of interactions that take place between the stakeholders in such networks of research and innovation: (1) Direct, in the sense of "personal" interactions that evolve around face-to-face encounters, or through phone, email or videoconferencing; (2) Indirect interactions through some kind of material "carrier": these include texts such as policy reports, protocols, books, music scores and questionnaires as well as artefacts such as websites, software, exhibitions, devices; and (3) Material interactions occur when potential stakeholders engage in a financial contribution, a contribution "in kind," or when facilities are shared (Spaapen and Van Drooge 2011). To research these interactions SIAMPI used a variety of methods, most of them stakeholder oriented. Among them were face-to-face interviews with academics and societal stakeholders and focus groups.

In a number of experimental studies in the Netherlands ideas developed in the SIAMPI project were tested, with a particular focus on hybrid forms of output and on the composition of the stakeholder context. ${ }^{3} \mathrm{Hy}$ brid output is a product or performance based on robust scientific work directed towards a broader audience than fellow researchers. Most often, this regards documents like books or articles that are not published in the regular scientific journals (for articles) or as scientific monographs (for books). There is also a growing variation of hybrid output such as films, (serious) games, protocols. In this paper, we limit ourselves to the various forms of written output.

We researched this by using the method of contextual response anaIysis (CRA) to trace the uptake of hybrid output in the environment of academic research groups. The idea is to see whether this approach, that we will explain in more detail further on, can help institutes to present their wider relevance in a convincing way in the context of the Dutch national evaluation system, the Standard Evaluation Protocol (SEP 2015-2021). In preparation of the national research evaluations (every six years in the Netherlands) all academic research institutes in the Nether- lands have to produce so-called self-evaluation reports in which they also address the wider context of research ${ }^{4}$. Also, a number of non-academic publicly funded research institutes, have taken the SEP as their evaluation model, often in adapted form.

The changing policy context is difficult for all academic researchers, but we noticed something interesting when talking to researchers in the areas of the social sciences and the humanities. Many of the fields in these areas, having difficulties with evaluation systems that primarily focus on bibliometric indicators, and on international comparison, saw in the shifting focus in evaluation discussions (to societal impact) an opportunity to develop assessment procedures that were more adequate to the work they did for variegated audiences. A lot of work in social sciences and humanities are oriented towards issues outside academia, serving variegated societal areas like health and wellbeing, politics, education, culture, migration, etc. ${ }^{5}$ That kind of work is often not very visible in the international databases that underpin the majority of the bibliometric indicators. That is the main reason the gathered deans of the Dutch humanities faculties decided in 2015 to start a project in which they wanted to develop a humanities specific evaluation protocol that at the same time would fit into the ruling national SEP protocol. Part of this paper is based on work we are conducting for that project which is expected to finish by the end of 2016. Next to that, we conducted a study for a broad social science institute of the University of Amsterdam. This way, we were able to take a closer look at research in the humanities and social sciences. In this paper, we focus on our review of the hybrid output of both the social science institute which has a broad palette of research interests and of a number of Dutch research schools in the humanities. Research schools organize researchers from various universities on the basis of their research interest. Most of these schools contain a variation of (sub)disciplines.

\section{VARIATION IN PUBLICATION PATTERNS AND STAKEHOLDER CONTEXT}

What the social science research institute and the humanities research schools have in common is that they are academic, but at the same time strive to conduct research that is not only scientifically excellent but also to a certain extent addresses socially relevant issues. In other words, they adhere to the growing demand from the government to become more relevant for societal challenges and questions. ${ }^{6}$ Research topics thus more and more have to be relevant for the scientific community and for society at large. And, all these institutes have to find

\footnotetext{
2 SIAMPI was an FP7 project aiming at finding new ways to assess social impact. It stands for Social Impact Assessment Methods for research and funding instruments through the study of Productive Interactions between science and society.

3 Studies included CPB Netherlands Bureau for Economic Policy Analysis, The Netherlands Institute for Social Research SCP, PBL Netherlands Environmental Assessment Agency, WODC Research and Documentation Centre of the Ministry of Security and Justice, Ministry of Foreign Affairs. More information can be found at www.adprins.nl and at the site of PBL for the following study: A.A.M. Prins, Contextual Response Analysis of reports of the Netherlands Environmental Assessment Agency PBL, Groningen 2012;

$4 \quad$ All publicly funded research in the Netherlands is evaluated once every six years via the so-called Standard Evaluation Protocol (SEP): http://www.vsnu.nl/sep $5 \quad$ See for example Federation 2017

$6 \quad$ In its vision on science and science policy for the next decade, the Dutch government distinguishes three main themes: excellent research, maximum social impact and cradle for young talent (Wetenschapsvisie 2025, The Hague 2014
} 
ways to involve stakeholders that are important for their work. These stakeholders vary from context to context, , and can vary from local, regional or national governments to schools, to hospitals to industry to NGO's or society at large. If such stakeholders are to be involved in developing the research agenda, it is necessary to know who are relevant stakeholders and what they are picking up from the research that is published. In the following, we will use a method, the Contextual Response Analysis (CRA) to gather information about the uptake of research output by the wider societal environment of an institute.

Arguably, the balance between the two goals of producing results for science and for society depends to a certain extent on the policy context in which these institutes operate, including reward systems and local incentives. Researchers in academia have been rewarded until now mainly for their contributions to the scientific debate, i.e. articles in international journals (for AISSR) and books (for the humanities faculties). Our approach aims at gaining more insight about the context by tracing output and getting information about the various stakeholders that are interested in the research produced by these institutes. The method has profited much from the general trend towards open access, which has made it much easier to trace variegated forms of output. As all of these institutes serve public goals, their output follows governmental (and in fact European) policy towards open access, and now as a rule is made publicly available, in print and via websites. The publications of the institutes we studied may thus reach different stakeholders both inside and outside academic circles and governments, which is pertinent to the evaluation of the innovation processes in which these institutes take part.

In the following we shortly present the social science institute and the humanities research schools. The Amsterdam Institute for Social Science Research (AISSR) unites all social science research of the University of Amsterdam. The research program focuses on the functioning of contemporary societies and their interrelationships from historical, comparative and empirical perspectives. The research program is organized into thematically focused groups with an anchor in one or more of the represented disciplines: sociology, geography, planning \& development studies, political science and anthropology. According to its mission, AISSR aims to contribute to public debates on key issues - specifically contributing to interventions that address pressing societal problems and to engage with relevant stakeholders.

In the case of AISSR the research we did was experimental in the sense that the management of this social science institute was interested to see whether our approach would give them new insights into the visibility of their output for a variety of stakeholders inside and outside academia. They agreed to participate in experimenting with our approach and use the outcomes in their respective self-evaluations. The study served to help both the development of our approach and to help the management of the institute to present themselves in a broader perspective related to their environment. ${ }^{7}$ The five sections of AISSR came forward with a list of 127 hybrid publications.

The examples of the research schools in the humanities are taken from a broader exploratory study aiming at the development of indicators of quality and relevance of research in the Humanities in The Nether- lands. The expected result of the exploratory study is a guide that helps researchers to work with the national protocol SEP 2015-2021 that in its current form was judged not fit for humanities research. The study, commissioned by the deans of all humanities faculties in The Netherlands, has invited the seventeen research schools to participate in the development of the indicators. The schools include a wide range of domains in the Humanities, including vested fields such as Archeology, Cultural History, Political History, Arts, Literature, and Theology and Religion Studies, and also multidisciplinary fields such as Cultural Studies or Media Studies.

The management of the humanities faculties we studied had a broader interest than the management of AISSR. They were looking for an approach that would help them to produce narratives for the national evaluation protocol SEP 2015-2021. So far, they found the protocol not fit for evaluation of the kind of research they conduct, and too much geared towards evaluation mechanisms used in the STEM fields. They were particularly interested in hybrid forms of output and ways to evaluate them because these kinds of products are becoming a typical output for humanities research, well aware that academic output could imply societal impact by uptake and use in non-academic settings.

It was decided to work according to a bottom up procedure, giving the field maximum opportunity to influence the approach. All humanities research schools received a questionnaire intended to elucidate characteristics of the research culture of each school asking what channels of communication (journals, publishers) are important for the domain of the school, and what the various academic and other audiences are that they aim at serving. The boards of the research schools appointed panels of prominent members of the schools in order to answer the questionnaire. This resulted in lists of journals and publishers, along with numerous suggestions of other types of research outcomes, such as catalogues, databases, software or documentaries. With regard to questions about hybrid publications the panels identified a number of specific publications that show characteristics of hybrid publications, addressing multidisciplinary audiences in academia and beyond.

While we cannot draw robust conclusions on the basis of the number of publications submitted (we did not ask for a specific number of publications), it is notable that there were differences between fields that might indicate differences in the use of hybrid publications. Eleven panels mentioned in total 156 different hybrid outputs, ranging from five for Archeology to 20 for Gender Studies and 47 for Arts. Hybrid outputs mostly included books and volumes but also catalogues and presentations of exhibitions (Arts), or compendia (Political History).

In both studies the selection of hybrid publications has been performed by researchers working in the respective fields of social sciences and humanities. However, as we shall argue on the basis of a brief systematic analysis of the societal and scientific reception of a selection of these publications, the hybrid characteristics can be demonstrated by showing the attention of stakeholders. For our argument, those publications have been selected that had notable societal impact (as indicated with CRA) and notable numbers of citations as indicated in Google Scholar as a measure of academic impact (Prins et al. 2016).

7 Some of the material presented here is also published in J.B. Spaapen, A. Prins, Contextual evaluation of multi-, inter-, and transdisciplinary research, in: Bernard Hubert et Nicole Mathieu et al. (Eds) Interdisciplinarités entre Natures et Sociétés, Peter Lang, 2016 


\section{THE METHOD: CRA}

In all cases we present here we gained insight in the variation of output and stakeholders by applying the Contextual Response Analysis (CRA). The analysis is based on an assumption similar to citation analysis, namely that identifiable and unique traces of a publication found on the internet and in specialized databases represent meaningful forms of use, in particular if these traces are linked to identifiable and relevant users. Firstly, traces on the internet and in specialized databases are not arising from publications but from the actions of users that can be seen as a response to the publication even though the nature of this response is unknown. Secondly, by paying close attention to the identification of the users, the response can be placed in context. Identifying users is in part necessary to exclude traces that cannot be regarded as a meaningful response such as those traces that emerge due to fully automated editing of websites. Identifying users also offers the opportunity to place the response into a context of use, such as characterized by the domain in which the response emerges (e.g. News media), or by the characterization of the user on the basis of social function or social-economic sector (e.g. Education, Individuals (Blogger), For-Profit Services etc.). An implication of the method is that the empirical data about use are restricted to traces of users that maintain institutional structures and related infrastructure, in the form of websites and databases. As with any analysis based on internet traces, the societal use by the unconnected population or by those who have little means or time to maintain websites or blogs goes unnoticed. However, the method attempts to focus particularly on the variety of use, comparing both the diversity of use of various products of one institute and the diversity among users among different institutes.

The Contextual Response Analysis is about interest and uptake. It has been developed to shed light on the stakeholder environment by identifying who in the environment of the research group or institute is interested in what is produced by the researchers. To be able to trace the interest of stakeholders and the uptake of articles, reports and other output (films, exhibitions), it is a crucial prerequisite that stakeholders of whatever background have open access to the output of a group or institute.

For this paper, we have focused on one specific form of output: publications. Specific keywords from titles of publications were scrutinised by using search engines such as Google, Yahoo and Bing and also Google Scholar. The results include the complete set of search results of each search engine. ${ }^{8}$ The websites, blogs and other (social media) traces that bear references to the publications are identified for various characteristics. These include the social or economic sector in which the referring site operates, such as for example the cultural sector (museums, cultural magazines or blogs devoted to culture), the sector of education, of government, of the health sector or other characterizations that are expected to be relevant for the mission of the investigated research unit. Next, the referring websites, blogs and other traces are also characte- rized for their function, i.e. their specific communicative role in the sector (does the site belong to a library or repository, a knowledge platform, a book seller, a professional association, a for- profit or non-profit enterprise or an event such as a lecture or conference, or a blog, a publisher etc.). This way the environment can be charted by identifying stakeholders using these publications, and knowledge can be gathered about the uptake of research and the diversity of stakeholders in non-academic as well as academic settings.

In all cases we found a variety of stakeholders related to the output.

This is evident from figures 1 and 2 that show response profiles of the most prominent sectors of stakeholders of the institutes, vis-a-vis a selected number of publications that we analyzed. The selection was done by the board of the institutes on the basis of what they perceived as publications that represent best the societal mission of their institute. The profiles are based on the number of stakeholders that refer to a specific publication. The CRA method excludes self-references as well as references by frequently referring book sellers, publishers and libraries. References in scientific journals are also excluded since indexing of scientific journals is more systematically done by Google Scholar than by Google or Bing, and would lead to confounded results in any comparison with Google Scholar results.

\section{ACADEMIC PUBLICATIONS AS HYBRIDS}

In the social sciences and humanities the route for societal use of scientific research is often conceived as taking place via popularizations or via reports that address the articulated demands of policy makers, clients and sponsors. However, the route of popularization implies for many a separation of academic and public debate. As our results also show, such a separation is not a prerequisite in the communication with non-academic users as the academic arguments are also relevant for these audiences.

This comes to the fore in the societal use made of hybrid publications. In the case of AISSR, stakeholders are found both in the societal domain, with sites regarding the higher education sector or other academic professionals (including for profit as well as public services) and in the scientific domain. Table 1 shows five frequently used publications of AISSR combined with the numbers of citations as derived via Google Scholar. Clearly, these are not popularizations but hybrid publications, intended as academic publications that serve both scholarly and societal needs. 
Table 1: Five frequently used AISSR publications used both on internet (Google and Bing) and cited by Google Scholar.

\begin{tabular}{|l|c|c|c|}
\hline & Kind of publication & $\begin{array}{l}\text { Societal use (= Number } \\
\text { of unique users)1) }\end{array}$ & $\begin{array}{l}\text { Scientific impact (Citations in } \\
\text { Google Scholar) }\end{array}$ \\
\hline $\begin{array}{l}\text { A. Mol, The Logic of Care, Health and the Problem of Patient Choice, 2008/ Logica van het } \\
\text { zorgen, v Gennep 2005 (Dutch version of the book) }\end{array}$ & Book & $48 / 36$ & $77 / 532$ \\
\hline $\begin{array}{l}\text { E. Tonkens, Mondige Burgers, Getemde } \\
\text { Professionals, Marktwerking, Vraagsturing en Professionaliteit in de Publieke Sector, NIZW, } \\
\mathbf{2 0 0 3} \\
\text { Dekker, Paul, T. Van der Meer, and I. De Goede. „Continu onderzoek burgerperspectieven." } \\
\text { Kwartaalbericht 2009 (2009). }\end{array}$ & Book Panel & 69 & 179 \\
\hline $\begin{array}{l}\text { P. Geschiere, The Perils of Belonging, Autochthony, Citizenship and Exclusion in Africa and } \\
\text { Europe, Univ. of Chicago Press, 2009 }\end{array}$ & Book & 37 & 16 \\
\hline $\begin{array}{l}\text { M. Wolsink, Wind power implementation, Renewable and Sustainable Energy Reviews, } \\
\text { 2007 }\end{array}$ & Scientific Article & 27 & 281 \\
\hline
\end{tabular}

1) Societal use without self-references as well as frequently referring booksellers, publishers, libraries and exclude references by scientific journals

The societal use of hybrid publications also emerges from a more detailed analysis of the stakeholders of the selected products analyzed here. More than one third of the stakeholders are active in the sector of education and research, of which half of them universities or research institutes, often also related to curricula in higher education. We also found stakeholders in a rather variegated context, ranging from democracy projects in Botswana, firms of lawyers in Bangladesh, to bloggers on developments in the National Health Service in the UK, to Dutch local authorities and management consultancies in health care.

In fig. 1 we show the results of a CRA of five hybrid publications of AISSR. Two publications in Dutch were written primarily with the dual purpose of reaching scientific as well as Dutch professional audiences. The book Logica van het Zorgen, the Dutch version of The Logic of Care, is an anthropological and philosophical study of the concept of care in the context of the commercialization of health care practices. It is used by professional organizations delivering or supporting health care, academic hospitals, higher education curricula and health care insurances. The book frequently reaches knowledge platforms on health care, blogs of health care professionals concerned with the developments in health care and also for profit services involved in innovating health care. Also various advocacy groups, including professional organizations and patient groups use this book. The sociological study Mondige Burgers (Expressive Citizens) aims to address the strained relation between vocal citizens and professional expertise, which again leads to use by for-profit organizations with a mission in innovating professional expertise, blogs, and advocacy groups. Two other AISSR studies with a more academic intent (a scholarly book by the anthropologist \& sociologist Geschiere, The Perils of Belonging, Autochthony, Citizenship and Exclusion in Africa and Europe, and a paper by the environmental geographer Wolsink, Wind Power Implementation in the scientific journal Renewable and Sustainable Energy Reviews) nevertheless have varied societal stakeholders. Firstly, these publications are used in curricula of universities and in research institutes. Also, advocacy groups are among the more frequent stakeholders. The book about citizenship draws attention from civil activist groups, academic circles outside universities involved in international politics, democracy and citizenship, while the paper about wind energy draws attention from advocacy groups pro and contra wind energy. The volume by Van der Meer is a series with yearly updates about citizens' experiences in relation to government and governance. The volumes are often used by local and regional governments and also by researchers.

Figure 1: Societal use of AISSR publications according to sector, numbers of stakeholders

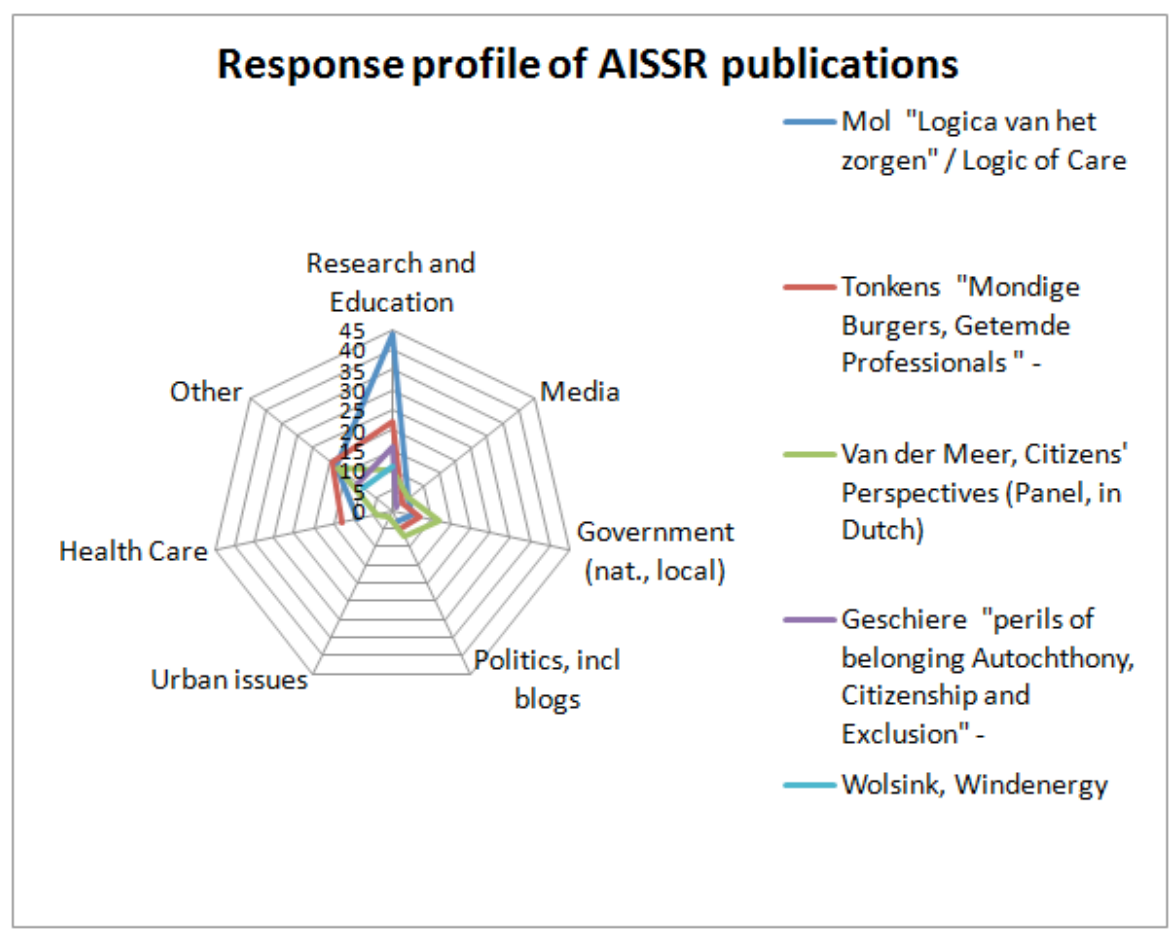


In a similar way, the hybrid characteristics of the publications in the Humanities can be demonstrated quantitatively. The 127 publications put forward by a number of panels have been investigated initially by using Google as a search engine. As this resulted in a vast number of different websites (over 13.000) a selection of the publications has been investigated further for various characteristics. This allows also excluding various search results that do not reflect the kind of productive interaction specified in the SIAMPI approach. Among these are web shops, booksellers, and also publishers, or libraries and repositories. As references found with generic search engines from scientific journals indicate communication within the field of academia rather than societal communication, these results also have been excluded.

Although each of these publications has drawn attention of societal stakeholders, their reception among academics too is noticeable in citations found with Google Scholar, characterizing the publications as hybrids (table 2).

Table 2: Thirteen frequently used Humanities publications used both on internet and cited by Google Scholar.

\begin{tabular}{|l|c|c|l|}
\hline & $\begin{array}{l}\text { Google } \\
\text { Scholar } \\
\text { cites }\end{array}$ & $\begin{array}{l}\text { \# net } \\
\text { societal } \\
\text { stakeholders }\end{array}$ & Panel \\
\hline $\begin{array}{l}\text { Annemarie Mol (2003) The Body } \\
\text { Multiple Duke University Press }\end{array}$ & 3359 & 86 & $\begin{array}{l}\text { Science and } \\
\text { Technology } \\
\text { Studies }\end{array}$ \\
\hline $\begin{array}{l}\text { José van Dijck. The Culture of } \\
\text { Connectivity: A Critical History of Social } \\
\text { Media. Oxford: Oxford UP, 2013. }\end{array}$ & 729 & 87 & $\begin{array}{l}\text { Literature } \\
\text { Studies }\end{array}$ \\
\hline $\begin{array}{l}\text { James C. Kennedy, Nieuw Babylon in } \\
\text { aanbouw. Nederland in de jaren zestig } \\
\text { (Amsterdam 1995: Boom) (1) }\end{array}$ & 280 & 132 & $\begin{array}{l}\text { Political } \\
\text { History }\end{array}$ \\
\hline $\begin{array}{l}\text { Piet de Rooy, Republiek van } \\
\text { rivaliteiten. Nederland sinds 1813 } \\
\text { (Amsterdam: Metz \& Schilt 2002) (2) }\end{array}$ & 151 & 46 & $\begin{array}{l}\text { Political } \\
\text { History }\end{array}$ \\
\hline $\begin{array}{l}\text { Ernst van de Wetering. Rembrandt. } \\
\text { The Painter at Work, AUP, 1996. }\end{array}$ & 150 & 106 & $\begin{array}{l}\text { Arts and Art } \\
\text { History }\end{array}$ \\
\hline $\begin{array}{l}\text { Trudy Dehue (2008) De depressie } \\
\text { epidemie, Amsterdam: Augustus }\end{array}$ & 103 & 206 & $\begin{array}{l}\text { Science and } \\
\text { Technology } \\
\text { Studies }\end{array}$ \\
\hline $\begin{array}{l}\text { Frits van Oostrom, Het woord van eer } \\
\text { (1987) \& Wereld in woorden (2013) }\end{array}$ & 74 & 22 & Philosophy \\
\hline $\begin{array}{l}\text { Leo Lucassen \& Jan Lucassen, } \\
\text { Winnaars en verliezers. Een Nuchtere } \\
\text { Balans Van Vifhonderd Jaar Immigratie } \\
\text { (Amsterdam: Prometheus, 2011) }\end{array}$ & 65 & 84 & $\begin{array}{l}\text { Economic } \\
\text { History }\end{array}$ \\
\hline $\begin{array}{l}\text { M. de Winkel, Fashion and fancy : } \\
\text { dress and meaning in Rembrandt's } \\
\text { paintings, Amsterdam (AUP) 2006 }\end{array}$ & 49 & 45 & $\begin{array}{l}\text { Arts and Art } \\
\text { History }\end{array}$ \\
\hline $\begin{array}{l}\text { Henk te Velde, Stijlen van } \\
\text { Leiderschap. Persoon en politieke van } \\
\text { Thorbecke tot Den Uyl (Amsterdam: } \\
\text { Wereldbibliotheek 2002) (3) }\end{array}$ & 41 & 47 & $\begin{array}{l}\text { Political } \\
\text { History }\end{array}$ \\
\hline $\begin{array}{l}\text { Marita Mathijsen, De gemaskerde eeuw. } \\
\text { Amsterdam, Ouerido, 2002. 268 pp. }\end{array}$ & 38 & 57 & $\begin{array}{l}\text { Cultural } \\
\text { History }\end{array}$ \\
\hline $\begin{array}{l}\text { Floris Cohen, Herschepping van de } \\
\text { wereld. Het Ontstaan Van De Moderne } \\
\text { Naturwetenschap Verklaard. } \\
\text { Amsterdam, Bert Bakker, 2008. 299 pp. }\end{array}$ & 35 & 66 & $\begin{array}{l}\text { Cultural } \\
\text { History }\end{array}$ \\
\hline $\begin{array}{l}\text { Wagenaar, Town planning in the } \\
\text { Netherlands since 1800, 2011 }\end{array}$ & 25 & History Art \\
\hline
\end{tabular}

From an academic perspective these publications reflect broad academic arguments of historical, philosophical and sociological background, often offering also critical perspectives. In this sense, the reception among academics may extend disciplinary boundaries.

Such broad perspectives extending disciplinary boundaries are widely valued by academic and non-academic audiences alike. This is the case with publications such as Cohen's book about the history of the natural sciences (Herschepping van de Wereld), Mathijsen's study of mentality in nineteenth century Netherlands, or Van Oostrom's history of court culture in The Netherlands (Woord van Eer).

Hybrids are often also topical to existing political and cultural debates, offering information, insights and perspectives on current or recent phenomena, such as Kennedy's study about Dutch culture in the 1960s (Nieuw Babylon), or Te Velde's study about leadership in Dutch politics (Stijlen van Leiderschap), or De Rooij's historical account of how rivalry has shaped Dutch politics throughout the last two centuries (Republiek van Rivaliteiten), or Van Dyck's Culture of Connectivity, a critical history of social media, such as Facebook, Twitter, Youtube and Wikipedia. They received much attention in blogs, curricula at other universities, or knowledge platforms in education. These historical books are not only reviewed in journals and books but also used by politicians, op-ed writers and (local) governments.

Topical is also Mol's book, The Body Multiple, addressing issues with an ethnographic analysis on the various perspectives and practices related to atherosclerosis giving insight in both doctors and patient narratives. The book has been reviewed in non-academic journals, and referred to in blogs (social media), knowledge platforms and by non-academic associations, in a wide variety of sectors.

Hybrid work may also imply or involve audiences in specific sectors. This is the case with Van de Wetering's book about working methods of Rembrandt. Since this book addresses also issues about authenticity, users in the cultural sector are keen to use and also discuss or debate this work because of the implications of assigning particular paintings or drawings to Rembrandt. Similar professional interest can be noted for the book on Town Planning by Wagenaar, with users in architecture and urban planning.

The topical nature of many hybrids can also lead to fierce debate. This is the case with Lucassen's book offering many facts and perspectives on the heavily contested issue of immigration, with references from bloggers, opinion makers in weeklies, politicians and interest groups working for refugees. Another example of a hybrid sparking fierce public debate is the historical and philosophical study about the rise of the diagnosis of depression by Dehue (Depressie Epidemie) ${ }^{9}$. The study received considerable media attention and also the Dutch award for best science communication book in 2009 by the Dutch Science Foundation NWO. The award praised the book to present "work that is relevant both scientifically and in society". The laudation read that "with historical analysis and well-funded methodology and analysis in science theory [...] and genuine apprehension about recent developments unmasks as unreliable ice what has been held for solid foundation". However, academic psychiatrists were less taken away by the book, criticizing it as "a poisonous broth that is harmful ... one is almost to compare it with Fitna" (a controversial film by the Dutch populist politician Geert Wilders). ${ }^{10}$ The book led to many appearances

9 Disclosure: Prins is the partner of Dehue. The selection of the book as a hybrid, however, was done by the panel of the school for Science, Culture and Technology Studies. 
on tv-shows and radio, interviews in and contributions to newspapers and weekly's, lectures for professional and non-professional audiences, and invitations for parliamentary special committees on health.

Figure 2 Societal profile of publications in Humanities prohibit stakeholder connections, it does complicate the evaluation of researchers' output. As institutes are competing with other institutes for funds and material support, within the university but also outside, they are always under pressure to perform evaluations that do not divert too much from what is prevailing. This tension shows

\section{Sectors of stakeholders for five Humanities publications}

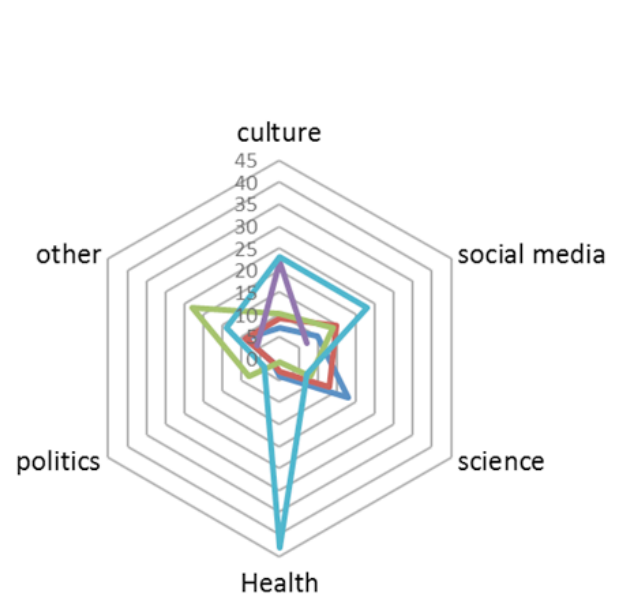

- Mol (2003) The Body

Multiple

—Van Dijck (2013) The Culture of Connectivity

- Kennedy (1995)Nieuw Babylon in aanbouw

—Van de Wetering (1996) Rembrandt. The Painter at Work

—Dehue (2008) De depressie epidemie for example in the mission statement of AISSR, where it reads that there is ample room for researchers to invest in creative and unusual approaches, rather than holding to a demand-driven research agenda. But at the same time, it is the policy of this institute to allow for a wide diversity of publication types, including monographs, contributions in newspapers as well as articles in journals. This enables groups and individual researchers to combine various publication channels.

We see something similar with the output in the Humanities research schools. The variegated output of these schools targets a wide variety of audiences, both within and outside academia. And, as the examples in table 2 show, there is a broad societal interest in the hybrid publications of these schools. And the societal uptake of each of these books is supported by the authors with public appearances in the form of lectures for various audiences, opeds in newspapers, essay contributions in magazines or media appearances on radio,

\section{STAKEHOLDER POLICIES: ACTIVELY MIXED PORTFOLIOS}

These variegated patterns of use show that the contexts in which institutes and researchers work are multi-faceted. Also, stakeholders researchers, professionals, policy makers, and citizens- are not operating in neutral environments or circumstances but are engaged in wider professional as well as political debates.

The awareness of researchers and their institutes for the contextual complexity becomes apparent in how the interactions with the environment are managed. Elsewhere, we have shown that policy research institutes outside academia may use more or less formal ways to organize interactions with environments (Spaapen and Prins 2016, Spaapen and Van Drooge, 2011, see also Hage et al 2010). However, in contrast to the explicitly organized stakeholder relations by policy research institutes, academic settings such as AISSR or schools in the Humanities appear to represent a distinct modality. Firstly, stakeholder connections are loosely organized by individual researchers or research groups. Secondly, stakeholder relations are maintained while at the same time fulfilling an academic mission. While this does not tv or in documentaries, blogs etc. Evidence for sure, that the context in which researchers operate is changing and that this influences their modus operandi.

While the hybrid publications noted above represent original scientific work, their critical characteristics makes them accessible for wider audiences and enable debates with relevant stakeholders. They also may help stakeholders to reflect on their professional practices. Apparently, the effectiveness of the stakeholder connections are not frustrated by the fact that researchers also claim room for 'pure' academic endeavors, nor are these latter held up by the authors engaging in societal debate via indirect forms of interactions such as newspaper columns combined with direct interactions with stakeholders through lectures, e-mail contacts or participation in committees. Clearly, whether intended or not, authors of hybrid work maintain a portfolio of different types of communication with the variety of stakeholders. Such portfolios are tailored for the specific sectors of the different stakeholders, depending for instance on the social characteristics of the sector, such as the degree of institutionalization or occurrence of larger organizations (political parties, governments, larger museums) as opposed to loose sets of individual users or small organizations such as artists, writers, general practitioners or health care workers). And it is time that this colorful palette gets recognized in regular evaluation procedures. 


\section{IMPLICATIONS OF DIVERSITY OF STAKEHOLDERS AND MIXED PORTFOLIOS FOR RESEARCH EVALUATION}

Evaluating academic research for both quality and relevance is challenging for everybody involved: researchers, stakeholders, evaluators and policy makers. Researchers have to find a balance in addressing the relevant audiences within and outside academia; while stakeholders have to engage early on in debates in order to be able to participate in shaping common research agenda's, evaluators have to broaden the way they assess the broader output of groups and institutes. And policy makers have to allow for more versatile evaluation procedures in which the context of research is somehow embedded. We have shown that there can be a rather large diversity among interested stakeholders, depending not only on the (multi)disciplinary background of the research but also on the very topic of research. This is apparent in both the environment of the Humanities research schools and that of AISSR, showing distinctly different users such as bloggers and book reviewers for historical books, or professionals in the relevant sectors for works on urban issues, politics or health.

Also, the variegated ways in which communication takes place via the mixed portfolios of researchers shows, that communication is multifaceted, depending on aspects such as topicality in general or specialized debates and the communicative characteristics of the fields in which stakeholders are working and are organized.

The current practices in evaluation often aim at the ranking and benchmarking of research units. This assumes also the possibility of comparison. However, as the examples show, the diversity of the stakeholders, and the multifaceted characteristics of the communication resist such comparison.

The CRA method we presented above serves two purposes at least. It aims at showing the uptake of research results in the societal context of research groups. And, it intends to help researchers to write up their societal impact in a more convincing way. This hopefully helps them in evaluation procedures that allow for a wider perspective on research than is usually the case in traditional metrics oriented evaluations that primarily are looking at output in the scientific literature. Those kinds of evaluations rest on a competitive view on science. But science is not a game, it is a serious business and society that is investing public money in research may expect that researchers are prepared to share and debate their work with interested audiences also outside their own field. Evaluation procedures in many countries start to recognize that as shown by the REF UK 2014 and the Dutch SEP 2015-2021, by allowing room in their protocols for assessment of research impact on society. In the Dutch case, this goes so far that there is a complete balance when it comes to weighing the scientific and the societal impact of research. CRA and other methods like the impact case studies used in the REF are meant to help all involved to gain more insight in the uptake and impact of research in society. Methods like CRA provide information that is not only systematic and robust but enables also to address issues of context and ambition of the research. In this sense, it is possible not only to look back to past performance but to use evaluations as formative events: as assessments of future opportunities and challenges.

\section{REFERENCES}

Bornmann, Lutz, (2013), What Is Societal Impact of Research and How Can It Be Assessed? A Literature Survey, Journal of the American Society for Information Science and Technology, 64(2):217-233, 2013

Federation 2017, Federation for the humanitiesand social sciencesCanada, Approachesto Assessing Impacts in the Humanitiesand Social Sciences, May2017

Hage, M., Leroy, P., Petersen, A.P., Stakeholder participation in environmental knowledge production. Futures 42.3 (2010): 254-264

Manville, Catriona et al., (2015), Assessing impact submissions for REF 2014: an evaluation Published by the RAND Corporation, Santa Monica, Calif., and Cambridge, UK

Prins, A. A., Costas, R., van Leeuwen, T. N., \& Wouters, P. F. (2016). Using Google Scholar in research evaluation of humanities and social science programs: A comparison with Web of Science data. Research Evaluation, rvv049.

Spaapen, J.B. and A.A.M. Prins, Final Report SIAMPI WP5 Health, with two case studies for NIVEL and LUMC, June 2010

Prins, A.A. M., Gebruik en gebruikers van WODC publicaties, Een bibliografische analyse van het WODC 2008-2010, Groningen 2012:

Prins, A.A.M., Contextual Response Analysis of reports of the Netherlands Environmental Assessment Agency PBL, Groningen 2012

Prins, A.A.M., J.B. Spaapen, Contextuele Respons Analyse van publicaties van het Sociaal en Cultureel Planbureau 2010-2015, Groningen 2016

Prins, A.A.M. Contextual Response Analysis of publications of the CPB Netherlands Bureau for Economic Policy Analysis, Groningen, 2015

Spaapen, Jack and Leonie van Drooge, Introducing 'productive interactions' in social impact assessment, (2011), Research Evaluation, 20(3), September 2011: 211-218

Spaapen, J.B. and A.A.M. Prins, Contextual evaluation of multi-, inter-, and transdisciplinary research, in: Bernard Hubert et Nicole Mathieu et al. (Eds) Interdisciplinarités entre Natures et Sociétés, Peter Lang, 2016

Wetenschapsvisie 2025, Keuzes voor de toekomst (Science Vision 2025, choices for the future), white paper of the Dutch government, published in november 2014, The Hague

\section{AUTHORS}

\section{A.A.M. PRINS}

Support in ResearchManagement

E: info@adprins.nl

\section{J.B. SPAAPEN}

KNAW (the Netherlands)

E: jack.spaapen@knaw.n 